\title{
Calculating Stress Intensity Factor (Mode I) for Composite Plate with Central Crack
}

\author{
Luay S. Al-Ansari, Ph.D \\ University of Kufa \\ College of Engineering \\ Mechanical Engineering Dept.
}

\author{
Hashim N. Al-Mahmud \\ University of Kufa \\ College of Engineering \\ Mechanical Engineering Dept.
}

\author{
Saddam K. Al-Raheem \\ University of Kufa \\ College of Engineering \\ Mechanical Engineering Dept.
}

\begin{abstract}
A Stress Intensity Factor (SIF) Mode I is calculated for longitudinal composite plate with dimensions $(104 \mathrm{~mm} \times 40$ $\mathrm{mm}$ ) and fiber volume fraction (37.5\%). The finite element method (FEM) (ANSYS) and MFree method are used for calculating the SIF of quarter model (i.e. $(52 \mathrm{~mm} \times 20 \mathrm{~mm}$ )) with constant displacement in $\mathrm{y}$ - direction that is applied at the ends of the plate. The crack length, material properties of fiber and material properties of matrix affect the SIF and these parameters are studied to understand the crack growth and the fracture mechanism in composite material. The value of SIF depends on the position of crack tip in additional to the material properties of fiber and matrix.
\end{abstract}

A comparison between the FEM and MFree method is made to study the advantages and disadvantages of each method and to choose the suitable method for calculating SIF for composite plate. Generally, there is a good agreement between the FEM and MFree method but there is a slightly difference between them specially when the crack length increases. This slight difference happens due to the calculation technique of SIF used in each method. This difference makes the FEM accurate than the MFree method unless increasing the number of nodes around the crack tip in MFree method.

\section{Keywords}

Stress Intensity Factor (SIF), Central Crack, Composite Plate, Longitudinal Composite Material, Volume Fraction, Finite Element Method (FEM), ANSYS, MFree Method.

\section{INTRODUCTION}

Due to their high strength to weight and stiffness to weight ratio, composite materials are being used extensively in the manufacturing of aerospace structures, automobile parts and even in construction and repair of buildings and bridges. Additional attributes like low thermal and electrical conductivity make them attractive replacement for many conventional metals. One area in which these materials lag behind metals is the resistance to fracture. Most often the thermosetting resins used as the matrix in fiber composites are inherently brittle and hence susceptible to fracture during service. The orthotropic nature of composites adds complexity to the analysis of these materials; however, there enough literature exists addressing the analysis procedure for structures made of composites [1].

According to linear elastic fracture mechanics (LEFM), the behavior of a crack in any brittle material can be characterized completely by a single parameter known as the stress intensity factor (SIF). The crack becomes unstable once a critical level of the SIF is reached and hence the determination of the SIF for a given loading and geometry is very important in the analysis of cracked structures. In unidirectional fiber composites, the behavior of cracks aligned along the fiber can be very well characterized by the SIF [2]. Different experimental techniques have been used in the past to determine the SIF for cracks in composites by various researchers. Singular stress field in the neighborhood of the periphery of an annular crack was studied by Gdoutos et al. [3]. The case of fiber debonding originating from the annular crack was also considered. In the study, they calculated KI and KII stress intensity factors and energy release rates. The energy release rate was derived by Liu and Kagawa [4] for an interfacial debonding of a crack in a ceramic-matrix composite and they used the Lame solution for an axisymmetric cylindrical fiber/matrix model. A numerical solution was carried out for the problem of interface crack by Aslantas and Tasgetiren [5]. Variations in the stress intensity factors KI and KII, with load position were obtained for various cases such as different combinations of material of coating layer and substrate, changes in the coefficient of friction on the surface. Xia et al. [6] analyzed fatigue crack initiation in SiC fiber (SCS-6) reinforced titanium on the basis of a finite element model. Their results showed that the formation of matrix crack largely depends on the applied stress and reaction layer thickness. A new method that obtains the complex stress intensity factor was presented by Bjerken and Persson, [7] (or alternatively the corresponding energy release rate and mode mixity) for an interface crack in a bimaterial using a minimum number of computations. Dirikolu and Aktas [8] carried out a comparative study regarding the determination of stress intensity factors for nonstandard thin composite plates. Carbon-epoxy composite plates were also considered for the study.

A number of methods have been used for the determination of stress intensity factors [9-13].One of these methods is a numerical method like Green's function, weight functions, boundary collocation, alternating method, integral transforms, continuous dislocations and finite elements methods. In this paper, the finite elements method and free mesh method (MFree Method) were used to calculate the stress intensity factor (KI) (Mode I) for unidirectional composite material.

\section{THE FINITE ELIMENET METHOD}

Aslantas [14] presented a numerical model developed for the analysis of a cylindrical element of matrix containing a single fiber. He used the finite element method (ANSYS 6.1) in order to create his model. He assumed a ring-shaped crack at interface of fiber and matrix. Both layers in the model were bonded perfectly with the exception of the crack faces. Contact elements, which had bonded feature, were used 
between fiber and matrix. He used displacement correlation method to calculate opening-mode and sliding-mode stress intensity factors. These results obtained from the analysis help to understand the debonding phenomenon between fiber and matrix interface. He discussed effects of the mechanical properties of fiber and matrix on direction of crack propagation.

Chandwani et al [15] used the ANSYS software to calculate the three dimensional stress intensity factors and energy release rate. They discussed, in their paper, the topology and meshing in relation to three dimensional cracks in additional to three dimensional crack growth. For three dimensional finite element method, Chin [16] investigated how a crack propagates and grows in a typical Ti-6Al-4V aerospace bracket. He simulated crack growth and computed the stresses and the stress-intensity factor. He compared the ANSYS results with the crack growth program FRANC3D.

A comparison between six models, calculating stress intensity factor (SIF) mode I for central cracked plate with uniform tensile stress, was made by Al-Ansari [17] in order to select the suitable model. He found that the quarter ANSYS model is a suitable model calculating stress intensity factor (SIF) mode I for central cracked plate with uniform tensile stress.

In this paper, the stress intensity factor (SIF) mode I for composite plate was computed using ANSYS software [17]. The procedure that was proposed by Phan [18] is used. Phan used a quarter two dimensions model for central cracked plate.

\section{THE MESHLESS (MFee) METHOD}

A meshless method is defined in a broad sense as a method where nodes are not required to be interconnected. Based on the formulation, meshless methods can generally be divided into two major categories: methods based on strong form formulations and methods based on weak form formulations. Most of the current meshless applications have been based on the Galerkin (global weak-form) formulation. Galerkin based meshless methods are similar to FEM in that they both require numerical integration to form the disrectised system of equations. However, unlike FEM where the basis functions are simple piecewise polynomials, the basis functions used for meshless methods are often highly nonlinear and not in closed form, as they must satisfy a number of stringent requirements [19]. Some commonly used methods for generating the basis functions include the moving least square (MLS) method [20], the reproducing kernel particle method (RKPM) [19] and point interpolation method [21].

Guiamatsia et.al. [22], observed delamination and matrix cracking by post-mortem analysis of laminated structures containing geometrical features such as notches or bolts. The finite element tools, that they used, cannot explicitly model an intralaminar matrix microcrack, except if the location of the damage is specified a priori. They used meshless technique, the Element-Free Galerkin (EFG) method, to utilize for the first time to simulate delamination (interlaminar) and intralaminar matrix microcracking in composite laminates.

The Meshless Local Petrov-Galerkin method (MLPG) was used by Ching and Batra [23] for determining of crack tip fields in linear elastostatics. They shown that the MLPG method augmented with the enriched basis functions and either the visibility or diffraction criterion successfully predicts the singular stress fields near a crack tip.

H. N. Azuz [24] presents an efficient numerical Meshless method in the formulation of the local weak form by Meshless Local Petrov-Galerkin "MLPG" method who is shape function derived using the Moving Least Squares "MLS" approximation. The modified MLPG formulation was employed for problems in Linear Elastic Fracture Mechanics "LEFM". He calculated the stress intensity factors for the mode-I and mode-II depending on the potentiality of the MLPG.

\section{THE MFee METHOD FORMULATION REQUIREMENTS}

Eight regular nodal configurations will be formed for a quarter model of the problem. For the sake of illustration, Fig. (1) exhibits the nodal distribution for one model where the width of the plate is $(52 \mathrm{~mm})$ and the height is $(20 \mathrm{~mm})$.

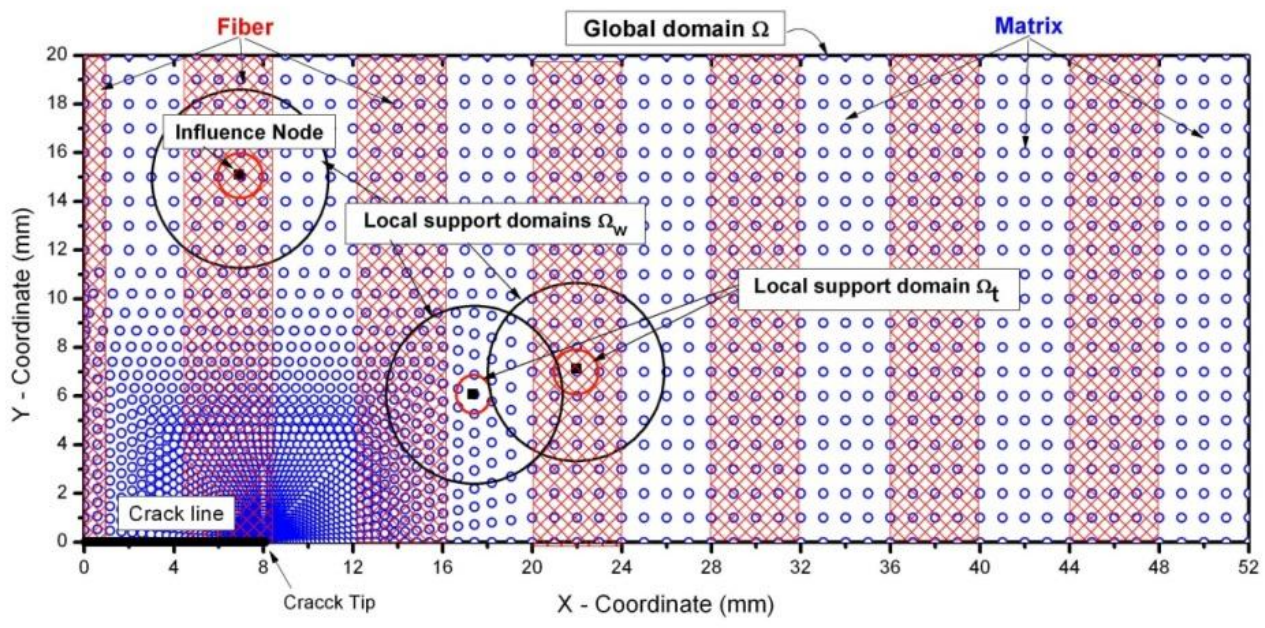

Fig. (1): MFree Modeling for Composite Material ( The Nodal Distribution for the Global Domain). 
The Meshless Local Petrov-Galerkin (MLPG) method formulation requirements for each of the predefined configurations involves the following:

For the Moving Least Squares (MLS) approximation and for each influence node, it is suggested to use the linear basis and the quartic spline weight function over a circular local support domains $(\Omega \mathrm{w})$ [24].

The test function constructed over a local sub-domain $(\Omega \mathrm{t})$ of size equals to the nodal spacing using the same quartic spline weight function.

$8 \times 8$ of Gaussian integration points are used in each local sub-domain for the domain integral, and 9 Gaussian integration points are used for the boundary integral.

The essential boundary conditions are enforced using $\alpha=1 \times 10^{16} \mathrm{~Pa} / \mathrm{m}$ as the penalty factor [21].

More details about theoretical formulation of the MLPG method can be seen in the literatures.

The total number of nodes for each quarter discretized model of( $52 \mathrm{mmlength} \times 20 \mathrm{~mm}$ height) are listed below in Table (1).

Table (1) Nodal Number for Each Model.

\begin{tabular}{|c|c|c|}
\hline Model & $\begin{array}{c}\text { Crack length (2a) } \\
(\mathrm{mm})\end{array}$ & $\begin{array}{c}\text { Total number of } \\
\text { nodes (N) }\end{array}$ \\
\hline 1 & 3 & 2200 \\
\hline 2 & 8 & 2411 \\
\hline 3 & 16 & 2522 \\
\hline 4 & 24 & 2534 \\
\hline 5 & 32 & 2534 \\
\hline 6 & 40 & 2534 \\
\hline 7 & 56 & 2534 \\
\hline 8 & & 2534 \\
\hline
\end{tabular}

It is important here to mention that MFree formulation technique has the potentiality to assemble/glue the two materials (Matrix\& Fiber) of the plate respectively through the implicit using local support domains in the formulation which takes the account to coalescence the whole strips as one domain, however, each strip still has its own properties.

\section{THE CALCULATION TECHNIQUE OF STRESS INTENSITY FACTOR}

In this work, the calculation of SIF using MLPG method had been accomplished using a special technique which is very adequate with general Meshless methods, and here is a deep explanation about it:

It is suggested to take a segment started exactly on the crack tip and outstretched straightly a head of the crack line $(\theta=0)$ having length less than of $2 \%$ of the crack length $(s \leq 0.02 a)$, then, a sufficient number of nodes will spread along this segment i.e. divided it to a sub-segments ( here the potentiality of Meshless methods appears). In order to calculate SIF, an investigation of the stress field near/ahead of the crack tip will be done through calculating the stress at each node on the gone segment, subsequently, plot on logarithmic scale these stresses against the effective radii $r_{s}$ to the crack tip which have the singular value of stress. Afterward, a linear curve fitting on the got data will be achieved which absolutely represent the behavior of stress field nearly around/ahead of the crack tip, hence, its easily to get the singular stress at the crack tip $(r \& 0)$ from which it possible to use the ASTM E399 equations to estimate SIFs, see Fig.(2). Theoretically, It's known that the slop of the fitted line equals to $(-0.5)$ where $K_{I}=\sigma \sqrt{2 \pi r}$.

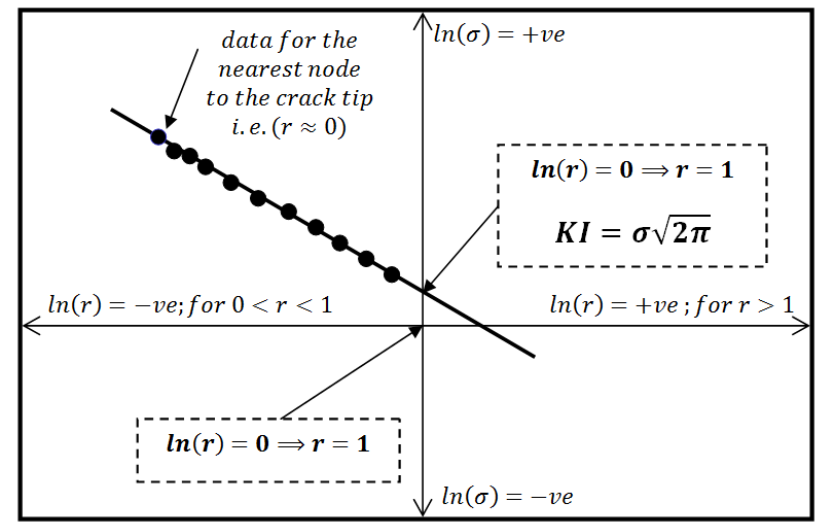

Fig.(2): SIFs Calculation Technique Where; the Fitted Line Represent the Behavior of the Singular Stress Field Which Theoretically Have a Slope of (-0.5).

Now it is important to explain that the calculated SIF for composite materials near/on interface line between two materials is not affected and it depends on the stress field near/around the influence node position since, in MFree Methods, the calculation technique depends on the size of the local support domain for each influence node which has the mutual-effect of a sufficient number of neighboring nodes included inside it which also provide the coalescence of the two materials, see Fig.(3). 


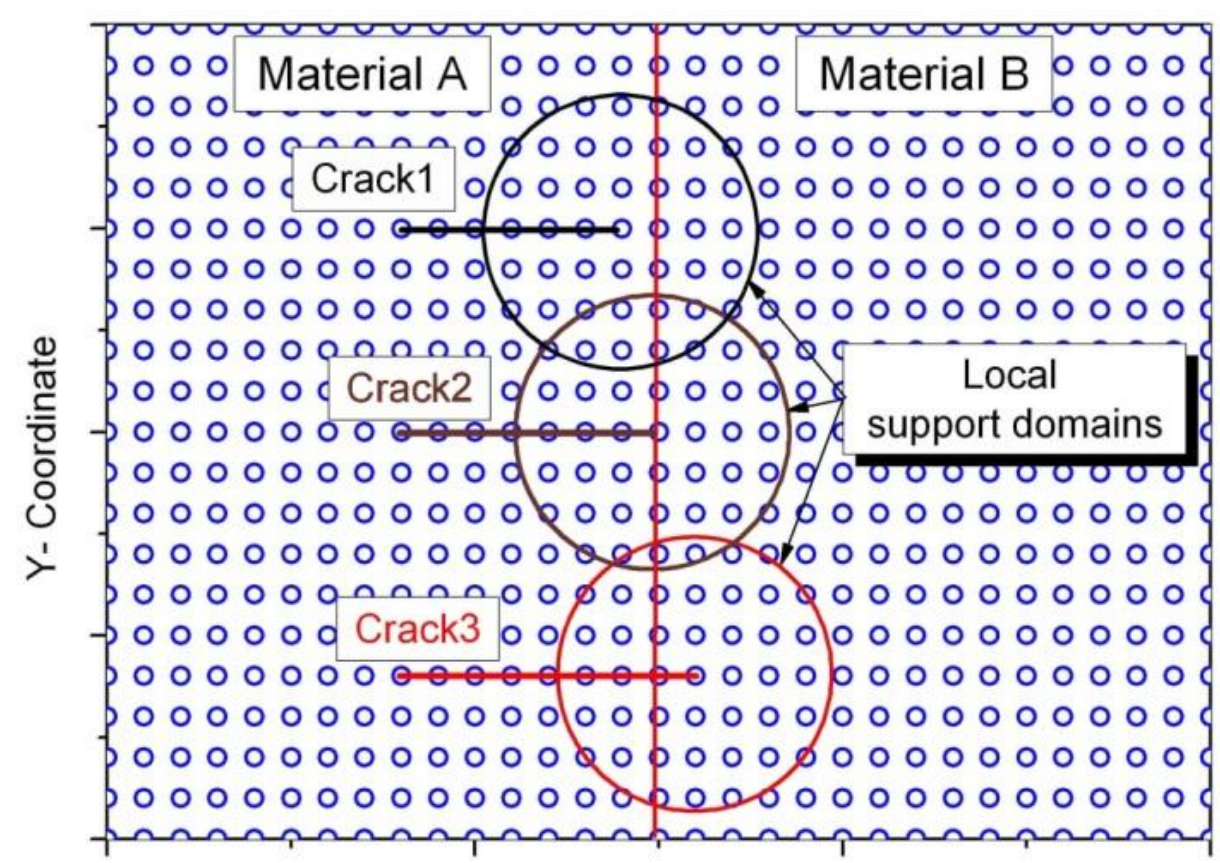

X-Coordinate

Fig.(3): MFree Handling for Interface Line in Composite Material With Cracks near/on it.

\section{CASE STUDY}

Several parameters are important in fracture of composite materials study like properties of fiber, properties of matrix, volume fraction of fiber, dimensions of fiber, dimensions of

Table (2): Required Properties of Composite Plate matrix, crack dimensions and dimensions of plate. In this work, the following parameters are used:

(1) Properties of composite Plate:

In this work, eight types of composite plate are used and their properties are maintained in Table (2).

\begin{tabular}{|c|c|c|c|c|c|c|c|c|}
\hline \multirow{2}{*}{ No. } & \multicolumn{4}{|c|}{ Properties of Fiber } & \multicolumn{3}{c|}{ Properties of Matrix } \\
\cline { 2 - 9 } & Name & $\begin{array}{c}\text { Modulus of } \\
\text { Elasticity } \\
\text { (MPas.) }\end{array}$ & $\begin{array}{c}\text { Spacipifi } \\
\text { c } \\
\text { Gravity }\end{array}$ & $\begin{array}{c}\text { Poisson } \\
\text { Ratio }\end{array}$ & Name & $\begin{array}{c}\text { Modulus of } \\
\text { Elasticity } \\
\text { (MPas.) }\end{array}$ & $\begin{array}{c}\text { Spacipific } \\
\text { Gravity }\end{array}$ & $\begin{array}{c}\text { Poisson } \\
\text { Ratio }\end{array}$ \\
\hline 1. & Glass & 83.5 & 2.5 & 0.3 & Epoxy & 3.3 & 1.25 & 0.4 \\
\hline 2. & Carbon (HS) & 300 & 1.75 & 0.32 & Epoxy & 3.3 & 1.25 & 0.4 \\
\hline 3. & Boron & 405 & 2.25 & 0.33 & Epoxy & 3.3 & 1.25 & 0.4 \\
\hline 4. & Carbon (HM) & 850 & 1.78 & 0.34 & Epoxy & 3.3 & 1.25 & 0.4 \\
\hline 5. & Glass & 83.5 & 2.5 & 0.3 & Nylon & 2.65 & 1.23 & 0.41 \\
\hline 6. & Carbon (HS) & 300 & 1.75 & 0.32 & Nylon & 2.65 & 1.23 & 0.41 \\
\hline 7. & Boron & 405 & 2.25 & 0.33 & Nylon & 2.65 & 1.23 & 0.41 \\
\hline 8. & Carbon (HM) & 850 & 1.78 & 0.34 & Nylon & 2.65 & 1.23 & 0.41 \\
\hline
\end{tabular}

(2) Dimensions of Plate:

The Dimensions of composite plate are $(104 \mathrm{~mm})$ width and $(40 \mathrm{~mm})$ height. But the dimensions of the ANSYS model and
MFree model are $(52 \mathrm{~mm})$ width and $(20 \mathrm{~mm})$ height as maintained before because the plate contains central crack (i.e. symmetry condition). In other words, we take the quarter 
plate only. While the thickness of plate is negligible because the two dimensional models were assumed. But the plate must be thin in order to apply the plane strain criteria.

(3) Volume Fraction of Fiber and Matrix:

The volume fraction of fiber $\left(\mathrm{V}_{\mathrm{f}}\right)$ is $(0.375)$ or $(37.5 \%)$ and the volume fraction of matrix $\left(\mathrm{V}_{\mathrm{m}}\right)$ is $(0.625)$ or $(62.5 \%)$. This volume fraction were chosen because the effect of fiber distribution on the stress intensity factor (SIF) appears significantly.

(4)Dimensions of Fiber and Matrix:

At the beginning, the diameter of fiber was assumed as (3 $\mathrm{mm})$. The dimensions of fiber are $(3 \mathrm{~mm})$ diameter and $(40$ $\mathrm{mm}$ ) height or length. The number of fibers can be calculated using the volume fraction of fiber and it was (13) fiber $\left(\mathrm{N}_{\text {fiber }}=13\right)$. Also, the number of matrices and width of matrix can be calculated using volume fraction of matrix. The number of matrices was (14) $\left(\mathrm{N}_{\text {fiber }}=14\right)$ and the width of matrix was $(4.643 \mathrm{~mm})$ and height or length of matrix was (40 $\mathrm{mm}$ ). Table (3) is summarized the dimensions of fiber and matrix.

Table (3): The Dimensions of Fiber and Matrix.

\begin{tabular}{|c|c|c|}
\hline & Fiber & Matrix \\
\hline Number & 13 & 14 \\
\hline Diameter or Width & $3 \mathrm{~mm}$ & $4.643 \mathrm{~mm}$ \\
\hline Height or Length & $40 \mathrm{~mm}$ & $40 \mathrm{~mm}$ \\
\hline Volume Fraction & $37.5 \%$ & $62.5 \%$ \\
\hline
\end{tabular}

(5) Crack Length (2a):

In this paper, eight crack length (2a) values were used (i.e. eight different configurations of ANSYS model and MFree model). The crack lengths (2a) were $(3,8,16,24,32,40,48$ and 56 ) $\mathrm{mm}$.

(6) The Applied Load:

The constant displacement in y-direction, that is applied on the upper edge of the composite plate, is used in this paper.

\section{RESULTE AND DISCUSSION}

\section{(1) SIF (Mode I) of Composite Plate:}

Figures $(4-11)$ show the comparison between the MFree method and FEM method (using ANSYS) for different materials and for different crack length. From these figures the SIF (Mode I) will increase and decrease according to the position of crack tip. If the crack tip is in fiber region the SIF will be larger than that was in the matrix region. That happens because the properties of fiber (specially Modulus of Elasticity) is larger than that of matrix. Also, when the materials of the composite plate (i.e. fiber and matrix) change, the curves will be similar in shape but different in the values. Also in MFree method, the SIF generally decreases slightly when the crack length increases. But in FEM, SIF increases slightly when the crack length increases. Therefore, the FEM is more accurate than MFee method because the calculation technique of SIF used in MFree method was not accurate like J-Integral method used in FEM.

(2) Effects of Crack Length and Modulus of Elasticity of Fiber on SIF (Mode I):

Figures $(12-13)$ show the comparison between the values of SIF at crack length $(0.006 \mathrm{~m})$ for the two matrices that are used in composite plate (i.e. Epoxy matrix and Nylon matrix) when the fiber type changes. In FEM (ANSYS) (i.e. Fig.(12)), when the matrix material is Epoxy the SIF will be larger than that of Nylon. Also, the SIF increases when the modulus of elasticity of fiber increases. But in MFree method (i.e. Fig.(13)), the SIF is the same for the two types of matrix material. But the SIF increases when the modulus of elasticity of fiber increases too. In the same way, Fig. (14) to Fig.(27) can be divided into two groups depending on the behavior of the increasing. The first group contains figures $(14,15,18,19,22,23,26$ and 27). In other words, the first group contains figures when the crack length (2a) is $(0.008,0.024,0.04$ and 0.056$) \mathrm{m}$. Generally in FEM (ANSYS), when the matrix material is Epoxy the SIF will be larger than that of Nylon and the SIF increases when the modulus of elasticity of fiber increases. Also, in MFree method, when the Modulus of Elasticity of fiber increases, the SIF be constant for the two types of matrix material. But the SIF, when the matrix is Epoxy, is larger than that when the matrix is Nylon. The second group contains figures $(16,17$, 20,21, 24 and 25). In other words, the second group contains figures when the crack length (2a) is $(0.016,0.032$ and 0.048$)$ $\mathrm{m}$. The SIF values are congruent when the matrix material is Epoxy or Nylon and for FEM or MFree method. But, the SIF increases when the Modulus of Elasticity of fiber increases.

This differences between the previous figures happened because the difference in the calculation method between the FEM (ANSYS) and MFree method and the position of crack tip. For example, when the crack length is $(0.016) \mathrm{m}$, the crack tip is in matrix region and the region before the crack tip is fiber region. In Mfree method (as mentioned before), the calculation procedure takes $(2 \%)$ of crack length after the crack tip (or ahead of crack tip) and that means the points used in calculation are still near the neighboring fiber region. Since the applied load is constant displacement on the upper edge, the stress in fiber region is greater than that in matrix region due to difference in Modulus of Elasticity. Therefore, SIF increases when the Modulus of Elasticity of fiber increases. In the FEM (ANSYS), three points are used to calculate SIF. These points are crack tip and two points in the region before the crack tip $[17,18]$. Therefore, SIF increases when the Modulus of Elasticity of fiber increases.

When the crack length is $(0.024) \mathrm{m}$, the crack tip is in matrix region and the region before the crack tip is matrix region too but the region after crack tip is approximately fiber region. The stress in the region before the crack tip is smaller than the that in the region after the crack tip. Therefore the SIF is constant when the Modulus of Elasticity of fiber increases. In the FEM (ANSYS), three points in the region before the crack tip is in matrix region. The SIF increases slightly when the Modulus of Elasticity of fiber increases. This increasing happens because number of nodes around the crack tip in FEM is greater that than used in MFree method and this make the FEM is more sensitive than MFree method in calculating the stresses around the crack tip.

(3) Comparison Between FEM and MFree Method:

Fig.(28) and Fig.(29) show the comparison between the SIF of four composite plates that matrix are Epoxy calculating by finite element method (ANSYS) and MFree method respectively. In Fig.(28), the value of SIF, calculating by finite element method, increase when the modulus of elasticity of fiber increases and the maximum SIF increase when the crack length increases. But in Fig.(29), the value of SIF, calculated by MFree method, increases when the modulus of elasticity of fiber increases and the maximum SIF decreases when the crack length increases. The same behavior shown in Fig.(30) and Fig.(31) when the matrix of composite plates is Nylon.

From the all figures, there is a good agreement between the finite element method and MFree method for calculating SIF of central crack in composite plate. 


\section{CONCLUSION}

From previous discussion, the following points can be concluded:

1- The SIF in longitudinal composite plate changes, depending on the position of crack tip, when the crack length increases. In other words, when the crack length increases, the value of SIF may be increase or decrease depending on the position of crack tip.

2- The changing of SIF, when the crack length increase, gives a good explanation for the fracture in composite materials and gives the answer for the question " why the crack cannot growth through the fiber and matrix in composite material".

3 - The changing in Modulus of Elasticity of fiber and/or matrix does not effect on the shape of changing the SIF but it effects the values of SIF.

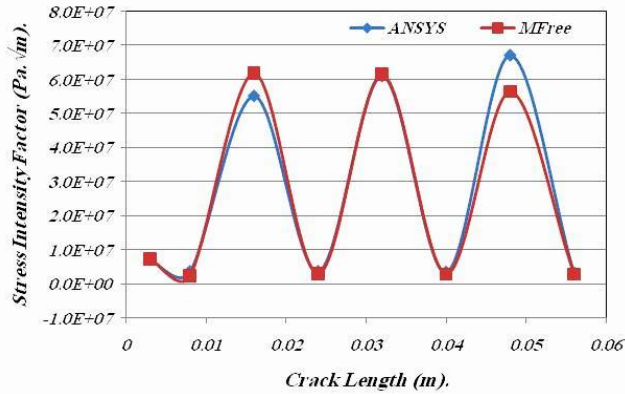

Fig.(4): Comparison Between SIF (Mode I) for Glass - Epoxy Composite Plate Calculating by MFree and FEM (Using ANSYS) With Varying Crack Length.

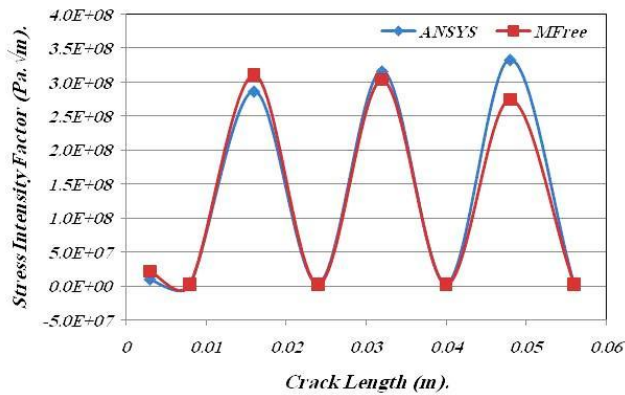

Fig.(6): Comparison Between SIF (Mode I) for Boron - Epoxy Composite Plate Calculating by MFree and FEM (Using ANSYS) With Varying Crack Length.

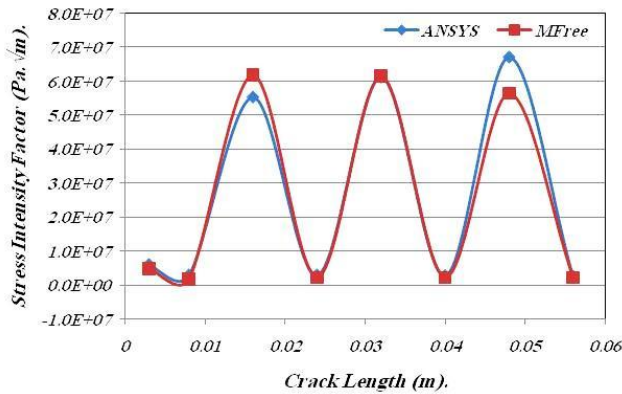

Fig.(8): Comparison Between SIF (Mode I) for Glass - Nylon Composite Plate Calculating by MFree and FEM (Using ANSYS) With Varying Crack Length.
4- The FEM is more accurate than the MFree method because of its ability to describe the interaction between the fiber and matrix properties and the calculation technique of SIF used in each method. The accuracy of MFree method can be increased by increasing the number of nodes, generally in the model and specially around the crack tip.

5- For the same Modulus of Elasticity of matrix, the SIF increases when the Modulus of Elasticity of fiber increases at any position of crack tip.

Finally, the volume fraction of fiber, crack orientation and type of applied load in longitudinal composite plate can be studied in future work to describe their effects in the SIF.

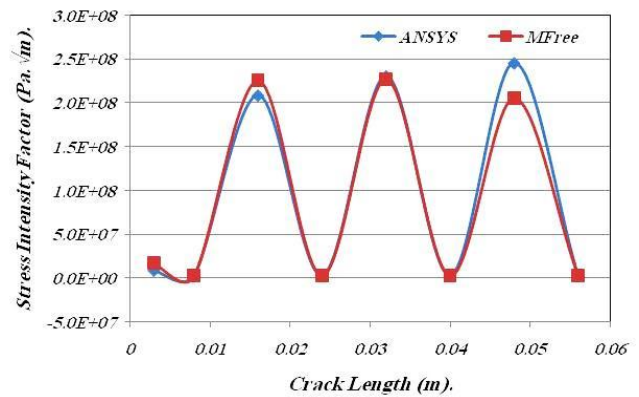

Fig.(5): Comparison Between SIF (Mode I) for Carbon (HS) - Epoxy Composite Plate Calculating by MFree and FEM (Using ANSYS) With Varying Crack Length.

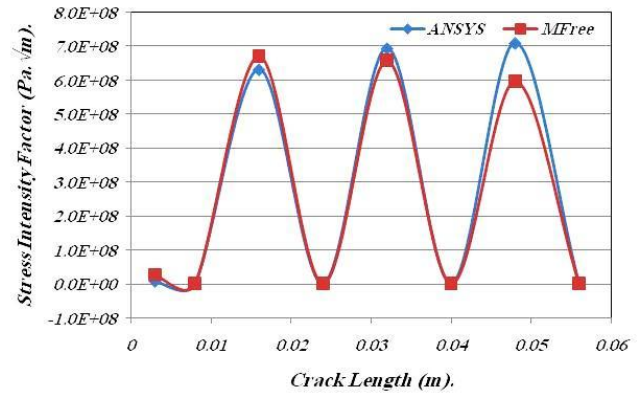

Fig.(7): Comparison Between SIF (Mode I) for Carbon (HM) - Epoxy Composite Plate Calculating by MFree and FEM (Using ANSYS) With Varying Crack Length.

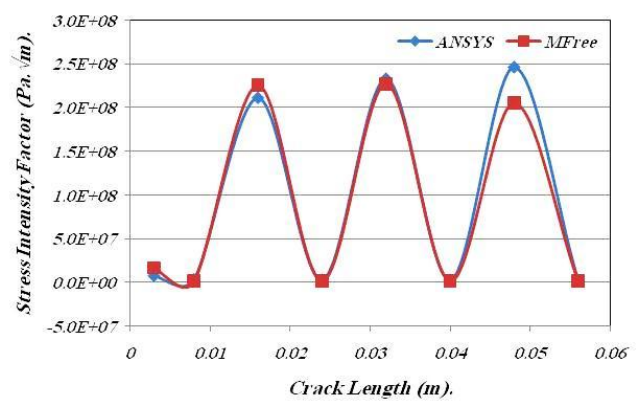

Fig.(9): Comparison Between SIF (Mode I) for Carbon (HS) - Nylon Composite Plate Calculating by MFree and FEM (Using ANSYS) With Varying Crack Length. 


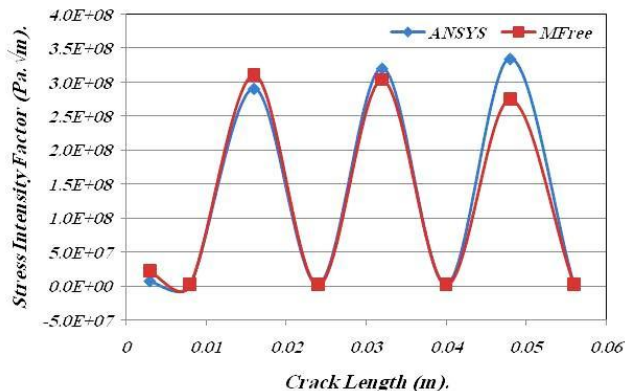

Fig.(10): Comparison Between SIF (Mode I) for Boron - Nylon Composite Plate Calculating by MFree and FEM (Using ANSYS) With Varying Crack Length.

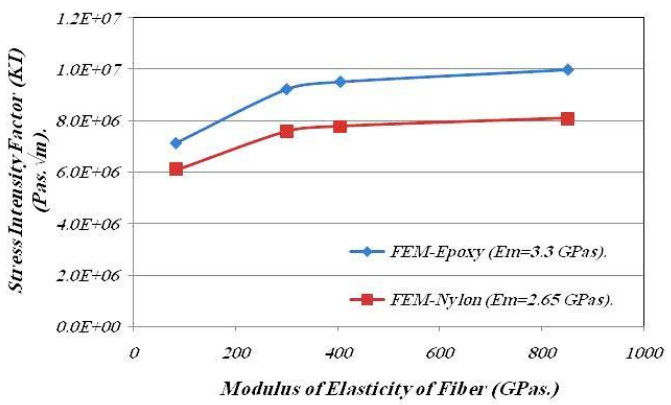

Fig.(12): Comparison Between The SIF (Mode I) for Composite Plate Calculating by FEM (Using ANSYS) With Varying Fiber's Modulus of Elasticity When the Crack Length is $(0.003) \mathrm{m}$.

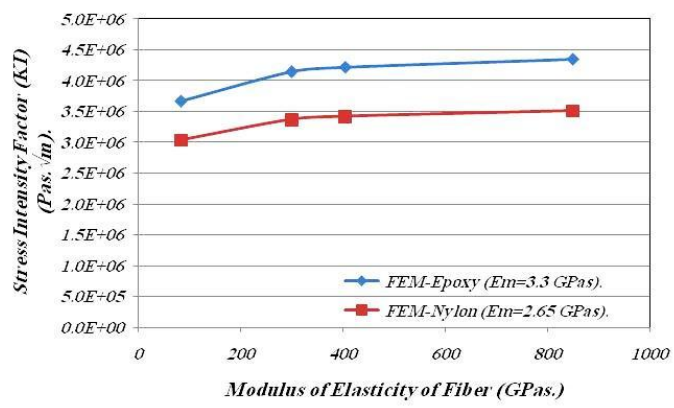

Fig.(14): Comparison Between The SIF (Mode I) for Composite Plate Calculating by FEM (Using ANSYS) With Varying Fiber's Modulus of Elasticity When the Crack Length is $(0.008) \mathrm{m}$.

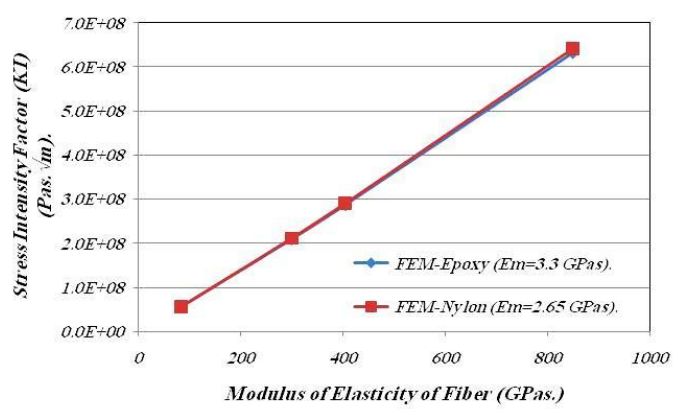

Fig.(16): Comparison Between The SIF (Mode I) for Composite Plate Calculating by FEM (Using ANSYS) With Varying Fiber's Modulus of Elasticity When the Crack Length is $(0.016) \mathrm{m}$.

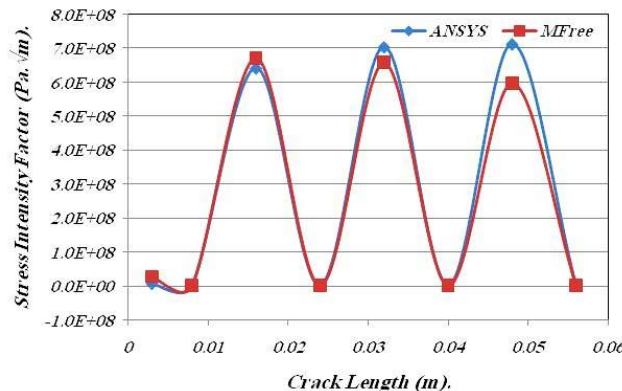

Fig.(11): Comparison Between SIF (Mode I) for Carbon (HM) - Nylon Composite Plate Calculating by MFree and FEM (Using ANSYS) With Varying Crack Length.

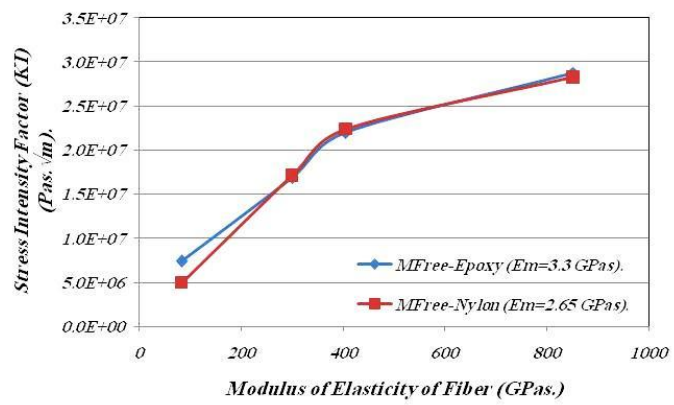

Fig.(13): Comparison Between The SIF (Mode I) for Composite Plate Calculating by MFree With Varying

Fiber's Modulus of Elasticity When the Crack Length is $(\mathbf{0 . 0 0 3}) \mathrm{m}$.

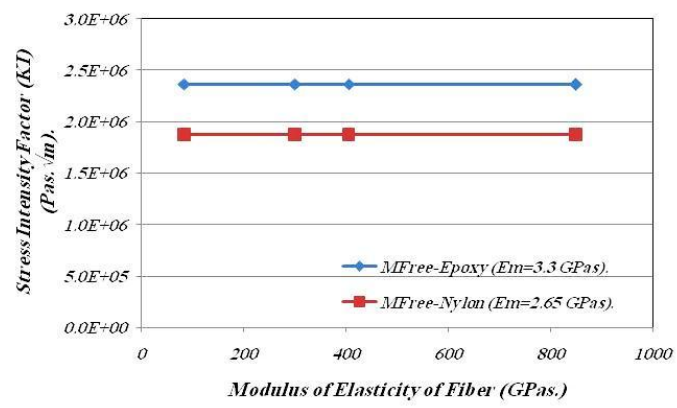

Fig.(15): Comparison Between The SIF (Mode I) for Composite Plate Calculating by MFree With Varying Fiber's Modulus of Elasticity When the Crack Length is $(\mathbf{0 . 0 0 8}) \mathrm{m}$.

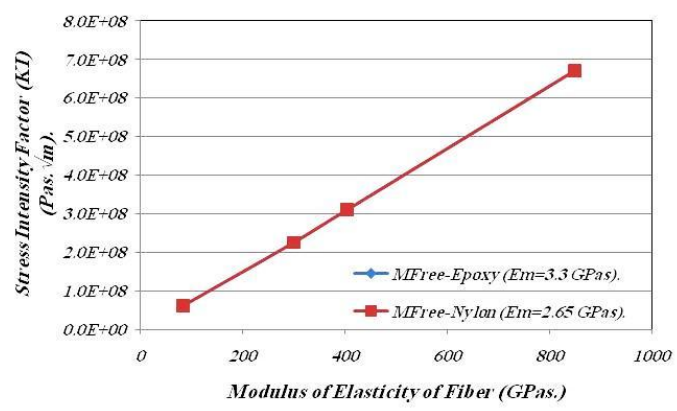

Fig.(17): Comparison Between The SIF (Mode I) for Composite Plate Calculating by MFree With Varying Fiber's Modulus of Elasticity When the Crack Length is $(0.016) \mathrm{m}$. 


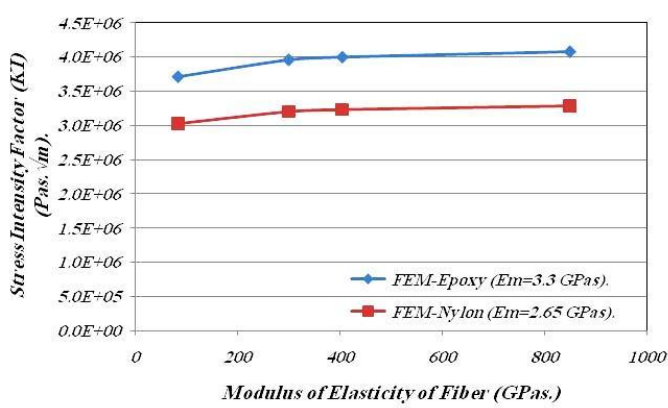

Fig.(18): Comparison Between The SIF (Mode I) for Composite Plate Calculating by FEM (Using ANSYS) With Varying Fiber's Modulus of Elasticity When the Crack Length is $(0.024) \mathrm{m}$.

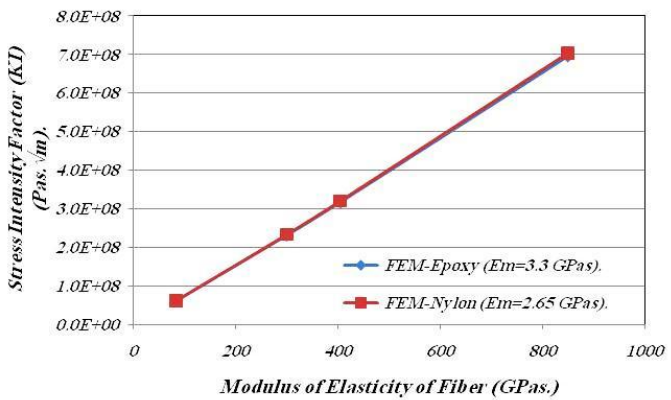

Fig.(20): Comparison Between The SIF (Mode I) for Composite Plate Calculating by FEM (Using ANSYS) With Varying Fiber's Modulus of Elasticity When the Crack Length is $(\mathbf{0 . 0 3 2}) \mathrm{m}$.

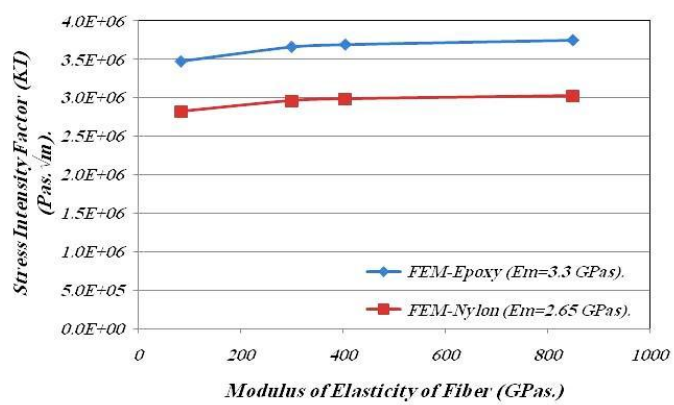

Fig.(22): Comparison Between The SIF (Mode I) for Composite Plate Calculating by FEM (Using ANSYS) With Varying Fiber's Modulus of Elasticity When the Crack Length is (0.04)m.

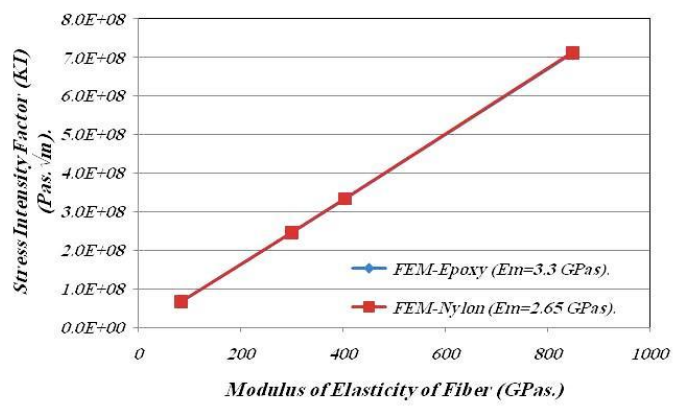

Fig.(24): Comparison Between The SIF (Mode I) for Composite Plate Calculating by FEM (Using ANSYS) With Varying Fiber's Modulus of Elasticity When the Crack Length is $(0.048) \mathrm{m}$.

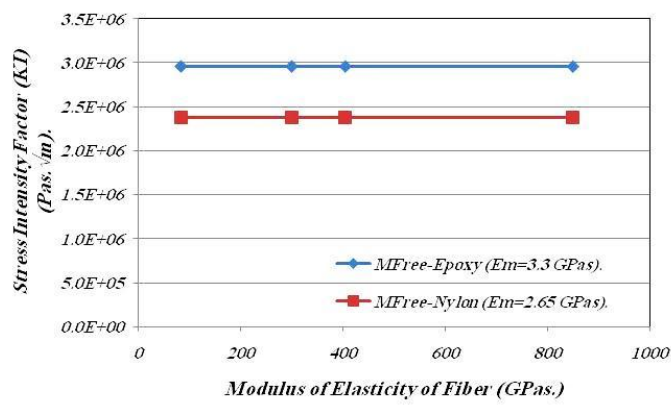

Fig.(19): Comparison Between The SIF (Mode I) for Composite Plate Calculating by MFree With Varying Fiber's Modulus of Elasticity When the Crack Length is $(\mathbf{0 . 0 2 4}) \mathrm{m}$.

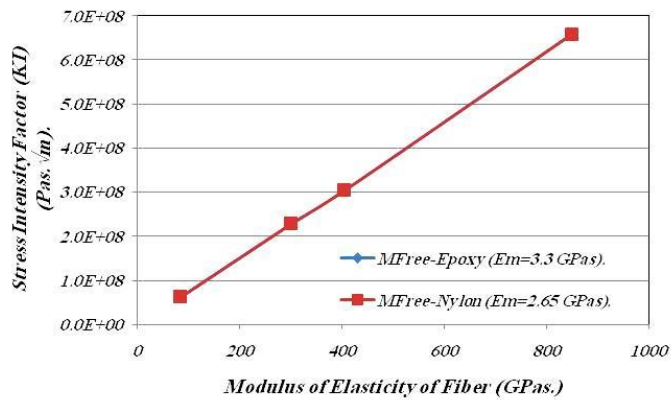

Fig.(21): Comparison Between The SIF (Mode I) for Composite Plate Calculating by MFree With Varying Fiber's Modulus of Elasticity When the Crack Length is $\mathbf{( 0 . 0 3 2 )} \mathrm{m}$.

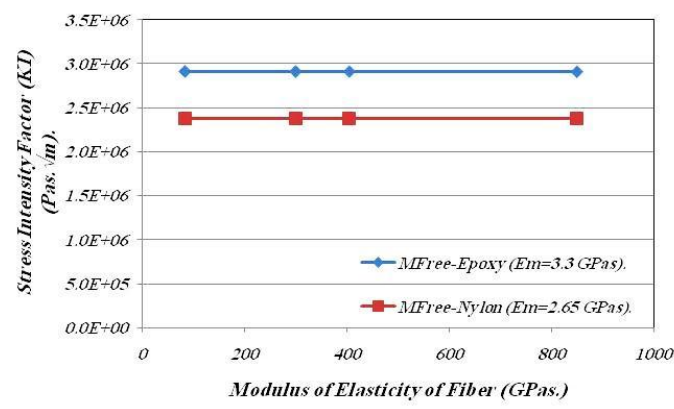

Fig.(23): Comparison Between The SIF (Mode I) for Composite Plate Calculating by MFree With Varying Fiber's Modulus of Elasticity When the Crack Length is $(0.04) \mathrm{m}$.

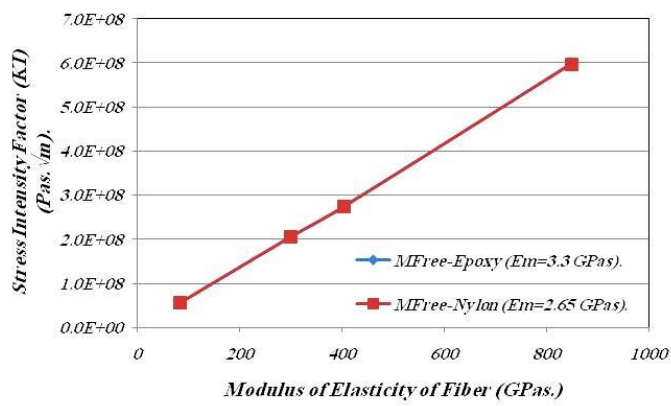

Fig.(25): Comparison Between The SIF (Mode I) for Composite Plate Calculating by MFree With Varying Fiber's Modulus of Elasticity When the Crack Length is $(0.048) \mathrm{m}$. 


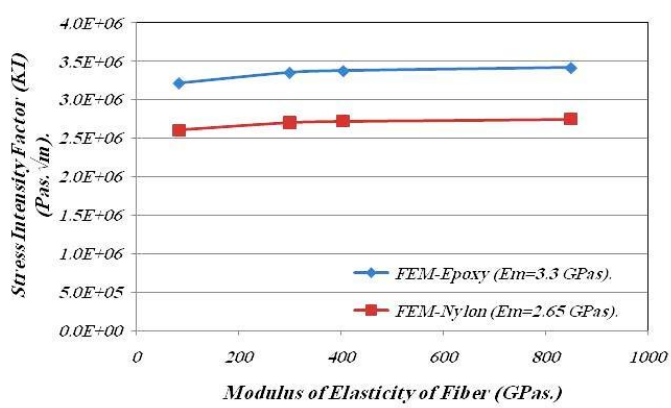

Fig.(26): Comparison Between The SIF (Mode I) for Composite Plate Calculating by FEM (Using ANSYS) With Varying Fiber's Modulus of Elasticity When the Crack Length is $(\mathbf{0 . 0 5 6}) \mathrm{m}$.

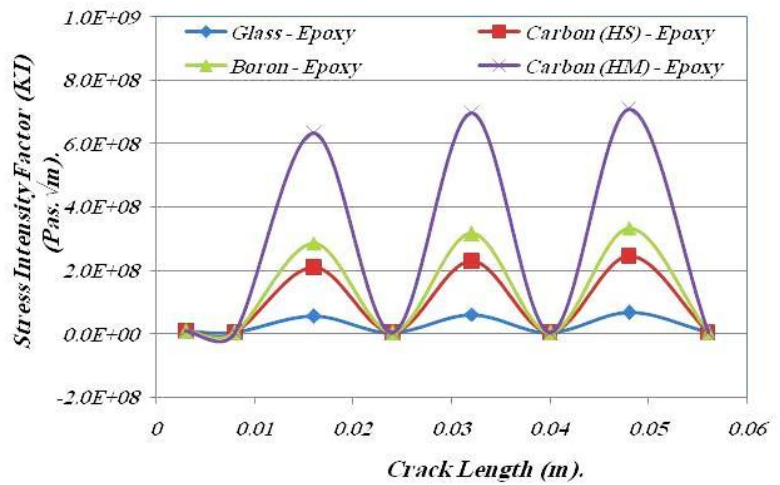

Fig.(28): Comparison Between the SIF (Mode I) for Composite Plate for Different Fiber Modulus of Elasticity Calculating by FEM (Using ANSYS) With Varying Crack Length When the Matrix is Epoxy.

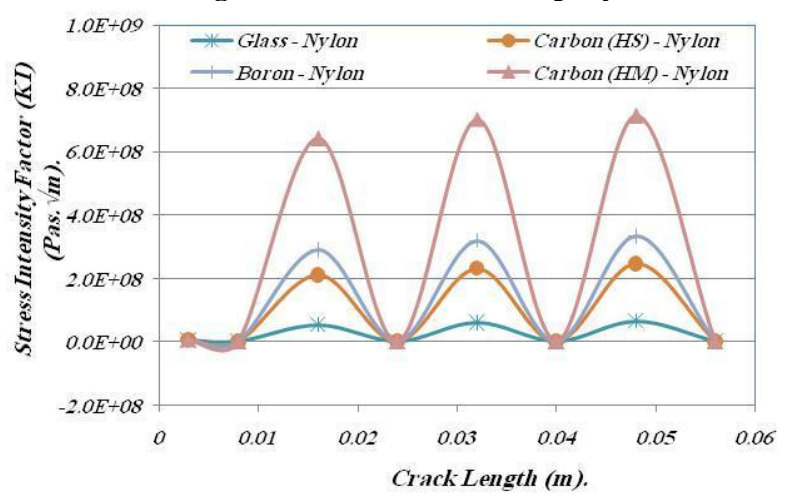

Fig.(30): Comparison Between the SIF (Mode I) for Composite Plate for Different Fiber Modulus of Elasticity Calculating by FEM (Using ANSYS) With Varying Crack Length When the Matrix is Nylon.

\section{REFERANCES}

[1] Agarwal, B. D. and Broutman, L. J. 1990. Analysis and Performance of Fiber Composites. John Wiley and Sons. New Jersey.

[2] Anderson, T. L. 1995. Fracture Mechanics-Fundamentals and Applications. CRC Press. Boca Ralton.

[3] Gdoutos, E.E., Giannakopoulou, A., Zacharopoulos, D.A., 1999. Stress and failure analysis of brittle matrix composites. Part II: Failure analysis. International Journal of Fracture 98. 279-291.

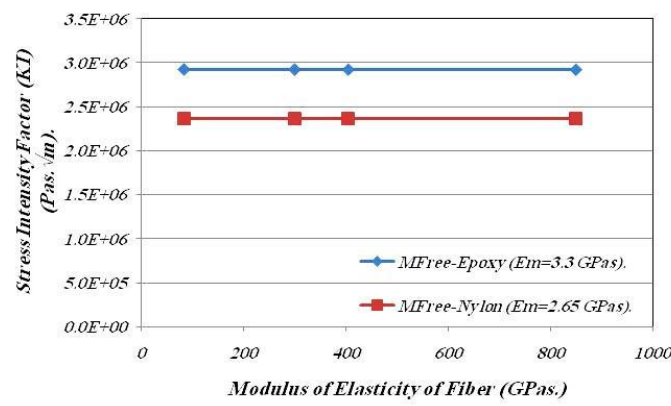

Fig.(27): Comparison Between The SIF (Mode I) for Composite Plate Calculating by MFree With Varying Fiber's Modulus of Elasticity When the Crack Length is $(\mathbf{0 . 0 5 6}) \mathrm{m}$.

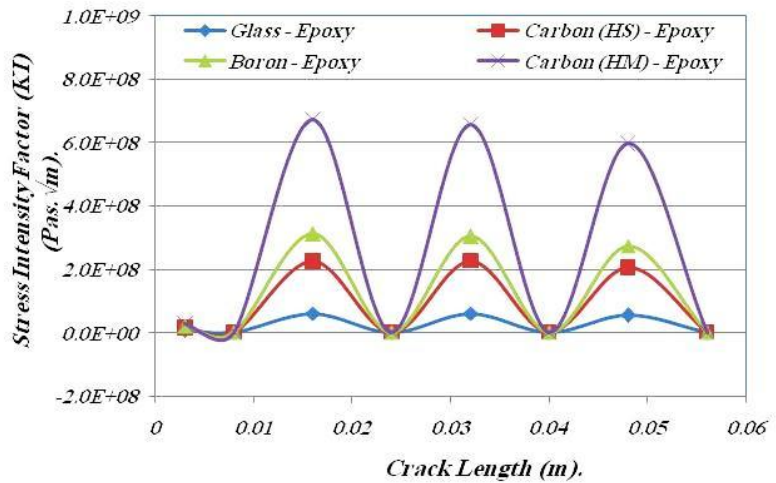

Fig.(29): Comparison Between the SIF (Mode I) for Composite Plate for Different Fiber Modulus of Elasticity Calculating by MFree Method With Varying Crack Length When the Matrix is Epoxy.

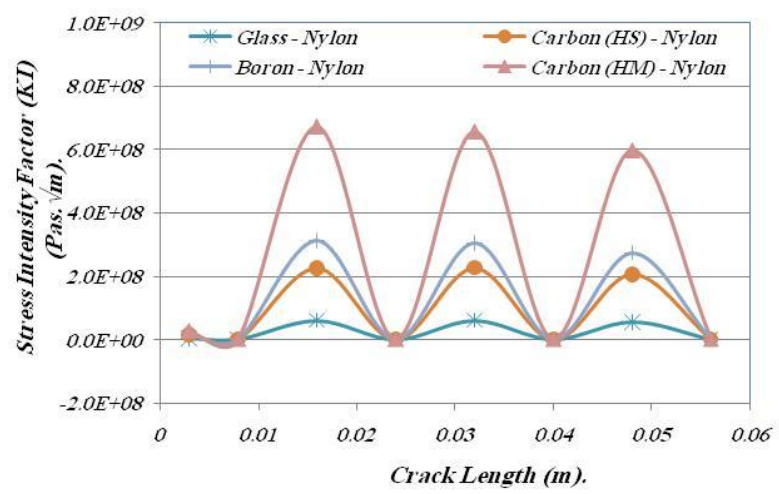

Fig.(31): Comparison Between the SIF (Mode I) for Composite Plate for Different Fiber Modulus of Elasticity Calculating by MFree Method With Varying Crack Length When the Matrix is Nylon.

[4] Liu, Y.F., Kagawa, Y., 2000. The energy release rate for an interfacial debond crack in a fiber pull-out model. Composites Science and Technology 60 (2). 167-171.

[5] Aslantas_, K., Tas_getiren, S., 2002. Debonding between coating and substrate due to rolling sliding contact. Materials and Design 43. 871-876.

[6] Xia, Z.H., Peters, P.W.M., Dudek, H.J., 2000. Finite element modelling of fatigue crack initiation in SiC-fiber reinforced titanium alloys. Composites Part A: Applied Science and Manufacturing 31 (10). 1031-1037.

[7] Bjerken, C., Persson, C., 2001. A numerical method for calculating stress intensity factors for interface cracks in bimaterials. Engineering Fracture Mechanics 68 (2). 235-246. 
[8] Dirikolu, M.H., Aktas_, A., 2000. Analytical and finite element comparisons of stress intensity factors of composite materials. Composite Structures 50 (1). 99102.

[9] D.E Rooke and D.J. Cartwright, 1979. Compendium of Stress Intensity Factors", Her Majesty's Stationery Office, London.

[10] E.E. Gdoutos, 2005. Fracture Mechanics: An Introduction. Springer.

[11] Gdoutos, E.E., 1990. Fracture Mechanics Criteria and Applications. Kluwer Academic Publishers.

[12] Murakami, Y. (ed.),1987. Stress Intensity Factors Handbook. Pergamon Press.

[13] Majid Mirzaei, Fracture Mechanics: Theory and Applications. Dept. of Mechanical Eng.. TMU. http://www.modares.ac.ir/eng/mmirzaei.

[14] Aslantas K. 2003. A different approach for calculation of stress intensity factors in continuous fiber reinforced metal matrix composites. International Journal of Solids and Structures 40. 7475-7481.

[15] R. Chandwani, M. Wiehahn and Ch. Timberll, 2004. 3D Fracture Mechanics In ANSYS. UK ANSYS Conference, Stratford Moat House. Warwickshire. UK. Nov. 15-16.

[16] Priscilla L. Chin, 2011. Stress Analysis, Crack Propagation and Stress Intensity Factor Computation of a Ti-6Al-4V Aerospace Bracket using ANSYS and FRANC3D. M. Sc. Degree. Rensselaer Polytechnic Institute. Hartford. Connecticut.

[17] L. S. Al-Ansari, 2012. Calculating Stress Intensity Factor (Mode I) for Plate with Central Crack: Review and
Comparison between Several Techniques of Calculations. Asian Transactions on Engineering,Vol.2; No.5.

[18] Dr. A. V. Phan, ANSYS TUTORIAL -2-D Fracture Analysis: ANSYS Release 7.0. University of South Alabama (Quarter Model).

[19.]Liu, W.K., and Chen, Y., 1995. Wavelet and multiple scale reproducing kernel Methods. international Journal for Numerical Methods in Fluids. 21. 901-916.

[20] Belytschko, T., Lu, Y.Y., and Gu, L., 1994. Element Free Galerkin Methods. International Journal for Numerical Methods in Engineering. 37. 229-256.

[21] Liu, G.R., 2003. Mesh free methods: moving beyond the finite element method. Boca Raton, Fla. CRC Press.

[22] Guiamatsia, B.G. Falzon, G.A.O. Davies, and L. Iannucci, 2009. Element-Free Galerkin modelling of composite damage. Composites Science and Technology. 69. $2640-2648$

[23] H.-K. Ching and R.C. Batra, 2001. Determination of Crack Tip Fields in Linear Elastostatics by the Meshless Local Petrov-Galerkin (MLPG) Method. CMES. Vol.2. No. 2. 273-289.

[24] H. N. Azuz, 2011. Linear Elastic Fracture Mechanics Analysis Using Meshless Local Petrov-Galerkin Method With Unconventional Support Domains. M.Sc. Thesis. University of Basrah.

[25] V.M.A. Leitão, C.J.S. Alves and C. Armando Duarte, 2007. Computational Methods in Applied SciencesADVANCES IN MESHFREE TECHNIQUES.Springer. 